\title{
Use of short prosthesis segments for brachiocephalic arteriovenous fistulas in elderly hemodialysis population
}

Jerzy Głowiński ${ }^{1}$, Jolanta Małyszko², Irena Głowińska², Michał Myśliwiec ${ }^{2}$

1Department of Vascular Surgery and Transplantology, Medical University of Bialystok, Poland

2Department of Nephrology and Transplantology, Medical University of Bialystok, Poland

Submitted: 12 February 2013

Accepted: 23 April 2013

Arch Med Sci 2014; 10, 1: 58-62

DOI: 10.5114/aoms.2013.35195

Copyright $\odot 2014$ Termedia \& Banach

\section{Abstract}

Introduction: The autogenous brachiocephalic fistula is a recognized secondary access for hemodialysis. However, veins in the antecubital fossa are often damaged, due to repeated venipunctures and subsequent scarring. Sometimes their anatomy does not enable successful arteriovenous fistula creation. In cases when the proximal part of the cephalic vein seemed patent, during ultrasound Doppler examination, we decided to use a short segment of $6 \mathrm{~mm}$ polytetrafluoroethylene graft to connect the vein with the brachial artery. We report our series of this procedure.

Material and methods: Over an 8-year period, 34 patients underwent such an operation. Grafts were anastomosed either to the end of the cephalic vein or to the side. The decision was made based on the vein condition: small-caliber veins were considered better for the end-to-side anastomosis. All procedures were performed under local anesthesia, and were well tolerated.

Results: Thirty-three fistulas were successfully cannulated at 2-8 weeks after the operation. Fistula patency rates were $84 \%, 73 \%$ and $55 \%$ at 12,24 and 36 months. Comparison of two anastomosis types showed differences, $50 \%$ and $62.8 \%$ at 36 months, yet without statistical significance ( $p=0.27$, log-rank test). Fistula patency was not influenced by patient's age, sex or comorbidities.

Conclusions: The described procedure provides satisfactory cumulative patency with an acceptable complication rate. It can enhance the number of cephalic veins used with its main advantages of simple surgical technique and low perioperative morbidity.

Key words: native fistula, vascular access, hemodialysis.

\section{Introduction}

Radial-cephalic wrist arteriovenous fistula (AVF) is a recognized vascular access for haemodialysis [1]. In many patients other autogenous options are possible [2]. The brachiocephalic autogenous fistula (BCAF) was proved to be a good, if not the best, option [3]. The cephalic vein lies superficially; in the elbow crease it can reach the brachial artery easily. Frequently, use of a median cubital vein is very helpful during the operation. Results are very satisfactory, particularly in elderly and diabetes patients [4]. Prevalence of chronic kidney disease is becoming a real problem in geriatrics. Novel markers, like neutrophil gelatinase-associated lipocalin (NGAL), kidney injury molecule-1 (KIM1) and cystatin C, proved their value in assessing renal function, partic-
Corresponding author:

Prof. Jolanta Malyszko

Department of Nephrology and Transplantology

Medical University

14 Zurawia St

15-540 Bialystok, Poland

Phone: +48 857409464

E-mail: jolmal@poczta.onet.pl 
ularly in elderly patients with another risk factor for kidney damage, such as hypertension or diabetes [5].

However, veins in the antecubital fossa are often damaged due to repeated venipunctures and subsequent scarring. Sometimes their anatomy does not enable successful AVF creation. In such cases basilic vein transposition or arteriovenous bypass graft were advised [6]. However, prolonged hemodialysis patient survival and need for patent vascular access compels vascular surgeons to look for more options. A simple method of brachiocephalic fistula with interposition of a short segment of polytetrafluoroethylene (PTFE) graft was proposed by Polo et al. [7]. The authors used a prosthesis to connect the side of the brachial artery to the side of the cephalic vein. Intimal hyperplasia $\mathrm{IIH}$ close to the graft-vein anastomosis was the most common complication observed in the study. End-to-side anastomoses develop IH more frequently than end-to-end anastomoses [8].

The study compared both anastomosis types and assessed the influence of different factors on long-term patency of the vascular access.

\section{Material and methods}

Over an 8-year period, 34 patients underwent an operation of brachiocephalic fistula using a short segment of a prosthesis.

Preoperative vein mapping with Doppler ultrasound was performed in all cases. When the cephalic vein was patent and the diameter was above $3 \mathrm{~mm}$ a patient was selected for brachiocephalic fistula. Inclusion criteria for graft interposition were: long distance between artery and vein, especially in obese individuals, with no chances for tensionfree anastomosis, fibrotic vein at the elbow level, thrombosis of the previously constructed BCAF, inappropriate for simple thrombectomy, with wide and patent proximal part of cephalic vein.

All patients gave their informed consent. The study was approved by the Medical University Ethic Committee.

A

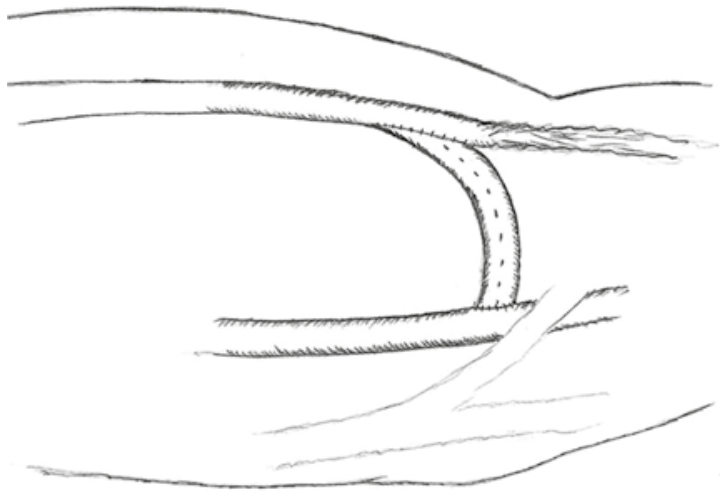

\section{Surgical technique}

Local anesthesia using 1\% lidocaine was applied. An oblique incision at the elbow crease was made in most cases. In a few patients two longitudinal skin incisions over the artery and vein were made. The distal part of the brachial artery was exposed in a typical way. A healthy segment of the cephalic vein was located and mobilized. The vein was flushed with heparinized saline. Arteriotomy utmost length was $6 \mathrm{~mm}$. A $3 \mathrm{~cm}$ to $6 \mathrm{~cm}$ graft segment ( $6 \mathrm{~mm}$ standard wall GORE-tex stretch, WL Gore) was used. Nineteen grafts were anastomosed to the end of the cephalic vein. End-to-side venous anastomosis was reserved for small-caliber veins, when end-to-end anastomosis might be unfeasible because of diameter disproportion. Venotomy length was $12-15 \mathrm{~mm}$, with caution to minimize the anastomosis angle. The venous end of the graft was cut at a bias to increase diameter. Blood stream was directed upwards, to avoid edema of the forearm (Figure 1). Antibiotic prophylaxis (cefuroxime) was used in all cases.

\section{Statistical analysis}

Kaplan-Meier method was used to calculate access survival. Cox regression was used for multivariate analysis of access survival. Two groups (anastomosis types) were compared by using a log-rank test. Statistical analysis was performed with Statistica 10 for Windows.

\section{Results}

Thirty-four graft-fistulas were constructed in 34 patients as a primary or secondary access. Patients' demographic data are collected in Table I. One case was early complicated with a hematoma and infection, requiring graft removal within one month. Thirty-three fistulas were successfully cannulated at 2-8 weeks after the operation. Dialysis centers were asked to use only the cephalic vein and avoid graft puncture.

\section{B}

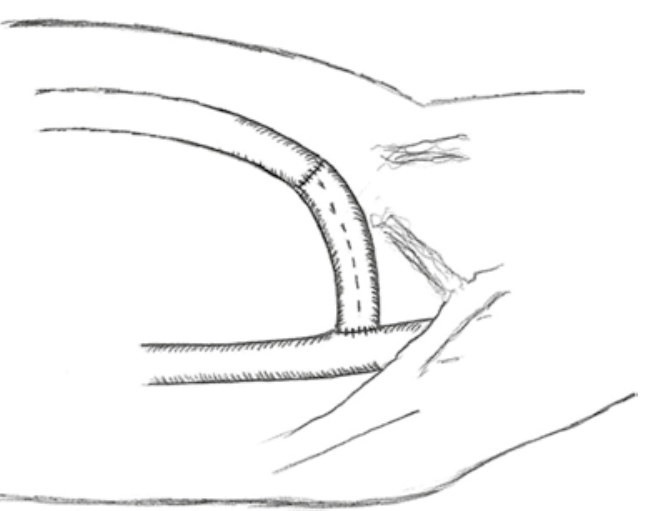

Figure 1. Different types of venous anastomosis. End-to-side (A) and end-to-end (B) 
Table I. Patient characteristics $(n=34)$

\begin{tabular}{|lc|}
\hline Variable & Value \\
\hline Age [years] & $68.3 \pm 10.6$ \\
\hline Sex (\% male) & 61.8 \\
\hline Diabetes mellitus [\%] & 23.5 \\
\hline Coronary heart disease [\%] & 29.4 \\
\hline Heart failure [\%] & 35.3 \\
\hline Obesity $\left(\mathrm{BMI}>30 \mathrm{~kg} / \mathrm{m}^{2}\right)[\%]$ & 32.4 \\
\hline
\end{tabular}

Doppler ultrasound examination was performed at 3 and 12 months (Figure 2). All prostheses were properly healed; no perigraft fluid was noted. Blood flow rates were between $660 \mathrm{ml} / \mathrm{min}$ and $2340 \mathrm{ml} /$ min (average $1101 \pm 372 \mathrm{ml} / \mathrm{min}$ ).

In 1 patient graft thrombosis was noted after 9 months. Thrombectomy was unsuccessful because of hyperplasia in both graft sides. The cephalic vein was severely narrowed and fibrotic in that area, but its proximal segment remained patent. The graft was removed and blood flow was restored using a segment of the basilic vein. One fistula required revision and balloon angioplasty of the subclavian vein at 17 months, because of arm edema. No other reoperations were performed in that series.

Steal syndrome was not observed in that series. We observed one case of hyperkinetic fistula, with flow rate of $2340 \mathrm{ml} / \mathrm{min}$.

Fistula patency rates were $84 \%, 73 \%$ and $55 \%$ at 12, 24 and 36 months (Figure 3). Comparison of two anastomosis types (Figure 4) showed differences, $50 \%$ and $62.8 \%$ at 36 months, yet without statistical significance ( $p=0.27$, log-rank test). Fistula patency was not influenced by patient's age, sex and comorbidities.

\section{Discussion}

Brachiocephalic fistula, being at low risk of thrombosis, is the access of first choice in the upper arm.
Primary patency of the fistulas was comparable to that of radiocephalic fistulas [9]. Unfortunately, the procedure is often aborted if the cephalic vein is found unsuitable, usually because of synechiae from prior venipuncture. Traditional options assume extensive operation (elevation/ transposition of basilic vein or graft implantation reaching an axillary vein), requiring general anesthesia [10]. We propose another possibility of vascular access: a relatively quick and simple procedure, satisfactory patency and saved basilic vein for future use.

Our original idea was to change traditional endto-side venous anastomosis into end-to-end, with better hemodynamics and fewer complications caused by intimal hyperplasia $(\mathrm{IH})$. In fact, IH was the reason for fistula failure rarely in our study. Most fistulas stopped because of destruction of the vein: aneurysmal dilatation, large subcutaneous hematomas, etc.

An antiproliferative effect of $1 \alpha-25$-dihydroxyvitamin $D_{3}$ on smooth muscle cells was recently studied. Hyperplasia developing in vascular anastomoses was significantly lowered [11]. That finding may be important because vitamin $D_{3}$ deficit is a common finding in hemodialysed patients.

Demographics (mean age $>65$ years) and comorbidities of patients involved in our study strongly suggested low-risk operation, preferably in local anesthesia. The relatively small procedure, with quick recovery and hardly any complications, can be performed in patients previously disqualified from surgery. Central venous catheters are the worst option for hemodialysis patients; their use increases all-cause, infection-related and cardiovascular mortality risk as compared to patients with an arteriovenous access - fistula or graft [12]. Thus, even elderly patients should have a chance for an optimal arteriovenous access.

Use of a short segment of PTFE is a rare option for arteriovenous fistula creation and reconstruc-

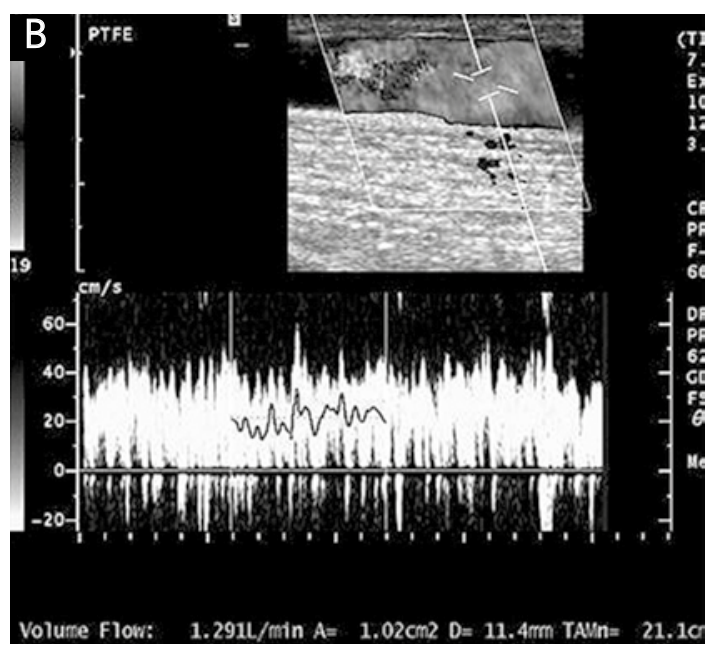

Figure 2. Duplex examination of prosthesis implanted in end-to-side fashion. B-mode shows properly healed graft (A). Doppler examination shows blood through cephalic vein a few centimeters above the anastomosis (B) 


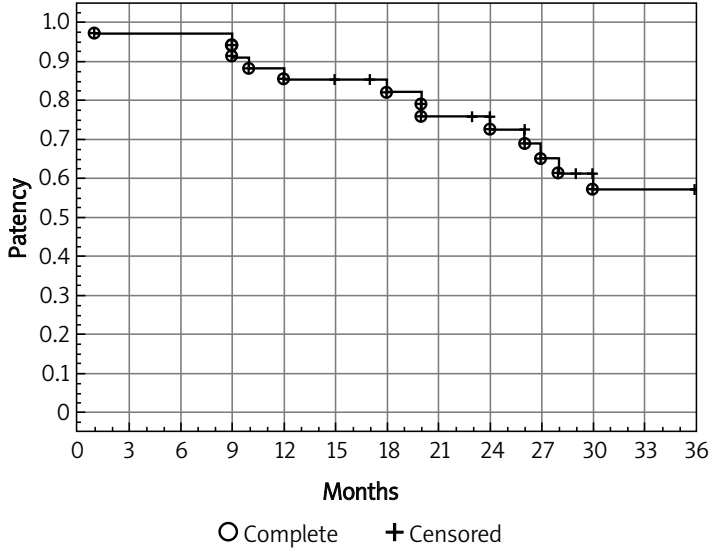

Figure 3. Patency rate for brachiocephalic fistula with graft interposition

tion. Prosthetic grafts for hemodialysis are often perceived as a quick solution for older, sicker dialysis patients who are not expected to outlive the limited life span of the graft [13]. Its main drawbacks, such as infections and thrombosis, were almost absent in our study. The infection rate was only $2.9 \%(n=1)$. That may be explained by a relatively small portion of artificial material used for an operation and cannulation done to the vein.

The idea to use short PTFE segments to repair the native fistula was described by Georgiadis et al. [14]. Grafts were used to bridge a stenotic/ thrombotic lesion and not for cannulation. They compared favorably to purely native repair and did not alter the autologous behavior of the initial access. Thus, "the venous capital" was spared for future use.

Average graft patency ranges from $24 \%$ to $54 \%$ at 24 months $[6,15]$. In our series the patency of vascular access was $73 \%$ at 24 months, which is comparable to native fistula [16]. Use of the prosthesis in our study had no negative impact on the final results. Comparison of arteriovenous fistulas (AVF) and arteriovenous grafts (AVG) has been studied recently; patency achieved by AVG and AVF at 24 months was $57 \%$ and $62 \%$ respectively [17].

We observed one aneurysmatic dilatation of the fistula. It affected a female patient with previous radial-cephalic fistula, and several additional procedures. She returned to hemodialysis after loss of a kidney transplanted a few years earlier. Ultrasound examination revealed significant dilatation of the brachial artery $(9 \mathrm{~mm})$ and cephalic vein (10 $\mathrm{mm}$ at elbow crease). We were afraid of excessive flow and/or steal syndrome after direct connection of such large vessels. A graft was supposed to work as a banding, used frequently for correction of high blood flow [18]. However, blood flow was $2340 \mathrm{ml} /$ min after 3 months [19].

Traditionally, we used grafts of $6 \mathrm{~mm}$ in diameter. With the above experience, we can recommend

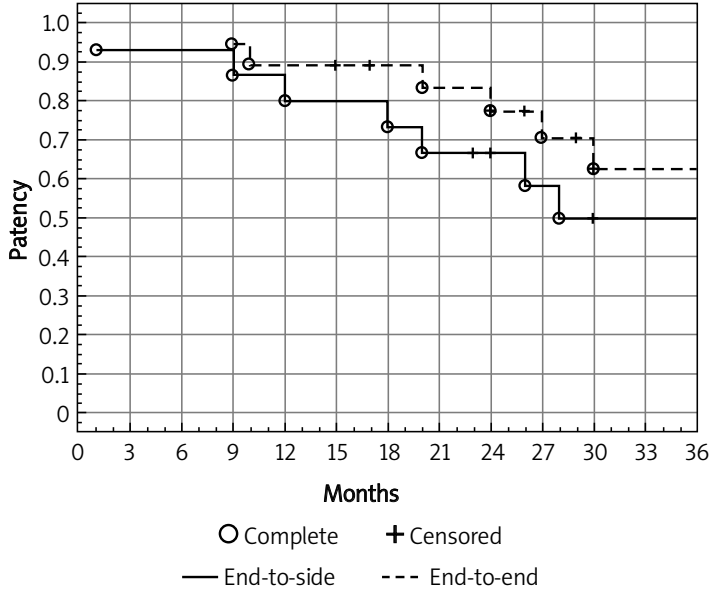

Figure 4. Differences in patency by anastomosis type

$5 \mathrm{~mm}$ tubes, at least in some cases, to avoid excessive flow and possible cardiotoxicity. Anastomosis with the distal part of the brachial artery spares the more proximal segment for future possible use for basilic vein transposition or classical prosthesis implantation.

Choice of the anastomosis type was decided during the operation by the surgeon. End-to-end anastomosis is alleged as better than end-to-side. However, it was not always possible to use it because of small caliber of the cephalic vein. Endto-side anastomosis was done to minimize the angle; it ranged from $15^{\circ}$ to $30^{\circ}$. The influence of anastomotic angle has been investigated in the latter type in a number of studies. Angles of $90^{\circ}, 45^{\circ}$ and $15^{\circ}$ were studied. The $15^{\circ}$ anastomosis showed the best hemodynamic properties [20]. In another study on ten patients, incorporation of a flow diffuser and a 15-degree anastomotic angle significantly increased patency of the prosthetic brachial artery to axillary vein grafts [21]. A sophisticated venous anastomosis resulted in unbelievable $100 \%$ patency at 24 months.

Elderly and diabetic patients with high comorbidity are becoming an important hemodialysis population. Particularly, patients with diabetes and endothelium dysfunction are prone to cardiovascular complications and thrombosis vascular access [22]. Destroyed arterial and venous vasculature raise a challenge to surgeons and nephrologists to create a satisfactory vascular access. Access surgery should be more flexible, to meet changing needs and possibilities.

The described procedure provides satisfactory cumulative patency with an acceptable complication rate. It can enhance the number of cephalic veins used with its main advantages of simple surgical technique, low perioperative morbidity and beneficial results. 


\section{References}

1. Vascular Access 2006 Work Group Clinical practice guidelines for vascular access. Am J Kidney Dis 2006; 48: S176-247.

2. Tordoir JH, Keuter X, Planken N, et al. Autogenous options in secondary and tertiary access for haemodialysis. Eur J Vasc Endovasc Surg 2006; 31: 661-6.

3. Oliver MJ, McCann RL, Indridason OS, et al. Comparison of transposed brachiobasilic fistulas to upper arm grafts and brachiocephalic fistulas. Kidney Int 2001; 60: 1532-9.

4. Murphy GJ, Nicholson ML. Autogeneous elbow fistulas: the effect of diabetes mellitus on maturation, patency, and complication rates. Eur J Vasc Endovasc Surg 2002; 23: 452-7.

5. Malyszko J, Bachorzewska-Gajewska H, laina-Levin N, et al. Markers of kidney function in the elderly in relation to the new CKD-EPI formula for estimation of glomerular filtration rate. Arch Med Sci 2011; 7: 658-64.

6. Chemla ES, Morsy MA. Is basilic vein transposition a real alternative to an arteriovenous bypass graft? A prospective study. Semin Dial 2008; 21: 352-6.

7. Polo JR, Vazquez R, Polo J, et al. Brachiocephalic jump graft fistula: an alternative for dialysis use of elbow crease veins. Am J Kid Dis 1999; 33: 904-9.

8. Li L, Terry CM, Shiu YT, et al. Neointimal hyperplasia associated with synthetic hemodialysis grafts. Kidney Int 2008; 74: 1247-61.

9. Zeebregts CJ, Tielliu IF, Hulsebos RG, et al. Determinants of failure of brachiocephalic elbow fistulas for haemodialysis. Eur J Vasc Endovasc Surg 2005; 30: 209-14.

10. Weale AR, Bevis P, Neary WD, et al. A comparison between transposed brachiobasilic arteriovenous fistulas and prosthetic brachioaxillary access grafts for vascular access for hemodialysis. J Vasc Surg 2007; 46: 997-1004

11. Yukerli I, Gokalp O, Kiray M, et al. Effect of $1 \alpha-25$-dihydroxyvitamin D3 on intimal hyperplasia developing in vascular anastomoses: a rabbit model. Arch Med Sci 2013; 9: 404-8.

12. Ocak G, Halbesma N, le Cessie S, et al. Haemodialysis catheters increase mortality as compared to arteriovenous accesses especially in elderly patients. Nephrol Dial Transplant 2011; 26: 2611-7.

13. Staramos DN, Lazarides MK, Tzilalis VD, et al. Patency of autologous and prosthetic arteriovenous fistulas in elderly patients. Eur J Surg 2000; 166: 777-81.

14. Georgiadis GS, Lazarides MK, Lambidis CD, et al. Use of short PTFE segments $(<6 \mathrm{~cm})$ compares favorably with pure autologous repair in failing or thrombosed native arteriovenous fistulas. J Vasc Surg 2005; 41: 76-81.

15. Gibson KD, Gillen DL, Caps MT, et al. Vascular access survival and incidence of revisions: a comparison of prosthetic grafts, simple autogenous fistulas, and venous transposition fistulas from the United States Renal Data System Dialysis Morbidity and Mortality Study. J Vasc Surg 2001; 34: 694-700.

16. Pflederer TA, Kwok S, Ketel BL, et al. A comparison of transposed brachiobasilic fistulae with nontransposed fistulae and grafts in the Fistula First era. Semin Dial 2008; 21: 357-63.

17. Disbrow DE, Cull DL, Carsten CG 3rd, et al. Comparison of arteriovenous fistulas and arteriovenous grafts in patients with favorable vascular anatomy and equivalent access to health care: is a reappraisal of the fistula first initiative indicated? J Am Coll Surg 2013; 216: 679-85.

18. Zanow J, Petzold $\mathrm{K}$, Petzold $\mathrm{M}$, et al. Flow reduction in high-flow arteriovenous access using intraoperative flow monitoring. J Vasc Surg 2006; 44: 1273-8.
19. Glowinski J, Glowinska I, Malyszko J, et al. Cardiotoxicity of arteriovenous fistula for hemodialysis. Nefrol Dial Pol 2012; 16: 143-5.

20. Staalsen $\mathrm{NH}$, Ulrich $\mathrm{M}$, Winther J, et al. The anastomosis angle does change the flow fields at vascular end-to-side anastomoses in vivo. J Vasc Surg 1995; 21: 460-71.

21. Hakaim AG, Nalbandian MN, Heller JK, et al. Improved patency of prosthetic arteriovenous grafts with an acute anastomotic angle and flow diffuser. J Vasc Surg 2003; 37: $1032-5$.

22. Koc-Zorawska E, Malyszko J, Zbroch E, et al. Vascular adhesion protein-1 and renalase in regard to diabetes in hemodialysis patients. Arch Med Sci 2012; 8: 1048-52. 